\title{
Analytical study of training program factors to develop the competency of regional operating officer (ROO) in the virtual service provider office (VSPO) in Thailand
}

\author{
Phongpisanu Boonda and Aree Preedeekul \\ Department of Curriculum and Instruction, Faculty of Education, \\ Pibulsongkram Rajabhat University, Phitsanulok, Thailand, and \\ Phataraphon Markmee \\ School of Health Science, Mae Fah Luang University, Chiang Rai, Thailand
}

\begin{abstract}
Purpose - Virtual regional service provider is a key management mechanism created to realize the health service system development plans and a mechanism established to bring about integration of all elements of the health system. However, a virtual service provider office (VSPO) to support the work of the executive has not yet been formally established, and there are no operations practitioners deployed yet, who are necessary to develop the competency of regional operating officer (ROO) in each province. The purpose of this paper is to analyze training program factors to develop the competency of ROO in the VSPO in Thailand.

Design/methodology/approach - This is a descriptive research that used structural equation model. The research sample consisted of 274 executives and 664 practitioners in the Vice Chief of the provincial health office under the 12 regions; executives' questionnaire and a VSPO questionnaire were used as tools for this study; data were statistically analyzed by three methods, namely, exploratory factor analysis (EFA), second-order confirmatory factor analysis (second-order CFA), and path analysis (PA).

Findings - The variable model was composed of ten factors, selected from 40 variables, which are as follows: service plan and personal administration, summary to present for administrators in the VSPO, network management and team building, summary to adjust strategies, key performance indicator (KPI) and action plan, new management skills, system thinking, analytical thinking, synthesis thinking, conflict management style, and leadership; presentation of methods and data for monitoring, presentation skill, conference management skill; researching, learning skill, communication skill exercise, action plan workshop, preparation to study in the fields workshop; fiscal and monetary, internal control and risk management; project management, monitoring, and data definition; and positive thinking, conflict management process, negotiation skill contingency management.

Originality/value - Ten factors of the variable model of training program factors to develop the competency of ROO in the VSPO in Thailand had high construct validity and they were analyzed using three methods, i.e. $\mathrm{EFA}$, second-order CFA and PA, that were appropriate to be used for developing a training program.

Keywords Thailand, Competency development, Virtual service provider office

Paper type Research paper

(C) Phongpisanu Boonda, Aree Preedeekul and Phataraphon Markmee. Published in the Journal of Health Reseach. Published by Emerald Publishing Limited. This article is published under the Creative Commons Attribution (CC BY 4.0) licence. Anyone may reproduce, distribute, translate and create derivative works of this article (for both commercial \& non-commercial purposes), subject to full attribution to the original publication and authors. The full terms of this licence may be seen at http://creativecommons.org/licences/ by/4.0/legalcode

This study was supported and supervised by the Sirindhorn College of Public Health, Phisanulok and The Second Regional Health Service of Ministry of Public Health, Thailand.
\end{abstract}


JHR
32,1

48

\section{Introduction}

In 2013, efforts to reform the health system of Thailand started with the aim of optimizing the management of the health system of the country, improving the management style in the area providing health services in the 12 regions, and promoting solidarity in the management and services of the health services network. In 2014, development of an operational infrastructure was initiated with the goal of establishing a service provider board to respond to the needs of the public health system. The Ministry of Public Health, Thailand has set the framework for the development of health care providers to have a clear and systematic health service system development plan aimed at improving the service levels from primary through secondary to tertiary and establishing excellent centers to be linked together into a network by geographical conditions and health care needs and communications.

This provides the opportunity to use and share the limited resources among all sectors and to efficiently support complex medical and public health problems. In addition, the regional service provider has a dimension of decentralization to deal with health problems in the area, including a mechanism for pastoral systems. At the same time, the regional service provider only has the inspector general of public health, supervisors, and the service provider board performing administration. However, a service provider office to support the work of the executives has not yet been perfectly established and there are no operations practitioners deployed. This is similar to having a virtual enterprise, but no clear model operates; and there is no clear format appropriate to the context.

A virtual organization is an organization involving detached and disseminated entities (from employees to entire enterprises) and requiring information technology to support their work and communication[1]. Virtual organizations do not represent a firm's attribute; but it can be considered as a different organizational form. Unfortunately, it is quite hard to find a precise and fixed definition of fundamental notions, such as virtual organization or virtual company[2]. For example, in terms of virtual organization, virtual enterprise or virtual corporation was first utilized in the early 1990s as demonstrated in the work of Jan Hopland, Roger N. Nagel, William H. Davidow, and Michael S. Malone[3, 4]. Table I allows us to understand more specifically their faintly distinctive theories.

In 2015, The Second Regional Health Service is one of the country's 12 service network zones, which is defined for virtual service provider office (VSPO); and it is responsible for Tak province, Phitsanulok province, Sukhothai province, Uttaradit province, and Phetchabun province[5]. This is similar to having a virtual enterprise, but no clear model operates in a virtual organization and there is no clear format appropriate to the context. As a virtual organization, it is a new form of organization that challenges to bring the application, but not the definition that was generally accepted by the virtual organization 15-20 years ago, when working at home was made possible by the use of technology[6, 7]. Since then, terms such as virtual office (VO), virtual classroom, and virtual corporation have appeared in the literature[8-10].

Table I.

Virtual organizations' views

\begin{tabular}{|c|c|c|c|}
\hline & Jan Hopland & Roger N. Nagel & $\begin{array}{l}\text { William H. Davidow and } \\
\text { Michael S. Malone }\end{array}$ \\
\hline Position & $\begin{array}{l}\text { Digital equipment corp. } \\
\text { executive }\end{array}$ & Management expert & $\begin{array}{l}\text { Authors of the virtual } \\
\text { corporation }\end{array}$ \\
\hline $\begin{array}{l}\text { Virtual } \\
\text { organization's } \\
\text { depiction }\end{array}$ & $\begin{array}{l}\text { A company that knows how to } \\
\text { utilize partnerships both inside } \\
\text { and outside its boundaries in } \\
\text { order to mobilize more assets } \\
\text { than it presently has on its own }\end{array}$ & $\begin{array}{l}\text { Take advantage of market } \\
\text { openings thanks to technology } \\
\text { which allows enterprises to } \\
\text { form temporary partnerships }\end{array}$ & $\begin{array}{l}\text { A broad and catch-all } \\
\text { term comprising } \\
\text { numerous management } \\
\text { ideas and trendy terms }\end{array}$ \\
\hline
\end{tabular}


The virtual service provider office management model (VSPOMM) for service plan (SP) in the Second Regional Health Service in Thailand was composed of seven factors from 74 selected variables, which were as follows: providing administration and management for everyone, regardless of time and place, as of media and technologies fit in any way, establishing administration by collaboration and clearing house, supporting technical services both in the system and outside the system in academic administration, instituting stakeholder support system in the network of general administration, freedom in budget administration, especially in the information technology development, personnel administration with new management and information technology skills, and operating support resources management, including management cockpit, document, and URL web link, and using web technology applications[5]. They put into consideration the concept of virtual reality created by a computer to establish an organization; so it may be of no physical shape, which is a characteristic that is different from traditional organizations in general. However, the definition of virtual organizations refers to the network of organizations linked by information technology in order to share operational skills and resources[11] through the use of telecommunications, technology, social, and community networks; which are interdependent cooperation, flexibility, trust, and self-organization[12]. The scope of the organization has an unclear boundary and location, which is expected to be useful in the adoption of VSPOMM for SP and in performing effectively.

"VSPO" is a new key management mechanism created to realize the health service system development plans and also a mechanism established to bring about integration of all elements of the health system. However, this VSPO to support the work of the executive has not yet been formally established and no operations practitioners are deployed; and there are no training programs yet, which are necessary to develop the competency of regional operating officer ( $\mathrm{ROO}$ ) in each province.

Researchers are also interested in creating a new training program to develop the competency of ROO in the VSPO, which is a new organizational model to solve the abovementioned problems. Research objective was to analyze training program factors to develop the competency (knowledge, skill, and practice for SP administration) of ROO in the VSPO in Thailand with the help of three methods: the analysis by exploratory factor analysis (EFA), the second-order confirmatory factor analysis (second-order CFA), and path analysis (PA).

\section{Methods}

Scope of research

Population. The population used in the development of the components is as follows:

(1) qualified member of the health services system in the VSPO of the regional health service in Thailand; and

(2) executives and practitioners in the Vice Chief of the Provincial Health Office in the health service virtualization of 12 regions of Thailand.

Contents. The contents included three core factors (knowledge, skills, and practices for SP administration) that were separated by seven factors of the training program factors to develop the competency of ROO in the VSPO in Thailand which were as follows: health sector reforms, regional health system, new management, leadership, partnership for regional health, competency of regional officer, and field learning.

Methods. This was a descriptive research that used the format of structural equation model research process, which was developed by the following three elements:

(1) Experts who created the master of studies and research-related documents, and then used it as a framework to create a query. The survey collected the data from a sample of experts and analyzed it with EFA.
Factors to

develop the competency of $\mathrm{ROO}$ in VSPO 
JHR

32,1

Sample. The samples used in the study to analyze training program factors to develop the competency of ROO in the VSPO in Thailand were the following two groups:

(1) A group of highly skilled executives of nearby health services system in the VSPO of the regional health service in Thailand. In total, 274 executives were selected purposively.

(2) A group of practitioners is required in the field of health services, VOs, since this research uses the query level 5 , which is commonly used in estimation techniques that are aimed at providing the most accurate parameter estimation.The margin of error (error bound: e) is small (between 0.01 and 0.25 ) and the other factors in the formula are constant. As a result, the sample is large. For population that is large, Equation (1) is used to yield a representative sample for proportions. The Cochran formula[13] is used for determining the sample size:

$$
n_{0}=\frac{Z^{2} p q}{e^{2}}
$$

where $n_{0}$ is the sample size, $Z^{2}$ is the abscissa of the normal curve that cuts off an area $\alpha$ at the tails $(1-\alpha$ equals the desired confidence level, for example, $Z$ is 2.576 for 99 percent confidence level[14]); $p$ is the estimated proportion of an attribute in the population that includes every individual from which it was drawn. It must have a known non-zero chance of being included in it. These chances should be equal. We would like the choices to be made independently; in other words, the choice of one region will not affect the chance of 11 regions being chosen; and $q$ is $1-p .(p)(q)$ are the estimate of variance[15]; $e$ is the desired level of precision with maximum error not more than 0.045 and a sample of 819 practitioners was selected by multistage random sampling that covered all geographical regions of Thailand, i.e. nationwide practitioners present in the 12 regions of VSPO of the regional health service in Thailand[16]:

$$
\therefore n=(2.576)^{2}(0.50)(1-0.50) /(0.045)^{2}=819
$$

Tools used in research. The instrument used for data collection is questionnaires that the researchers created. Two versions of the questionnaire that qualified to the query administrators and practitioners in the field offices of the virtual health services are as follows:

(1) Questionnaire for luminaries used to collect information for analyzing the components. It was a survey of the executive's opinions on the list of 40 variables on the form of the training program factors to develop the competency of ROO in the VSPO in Thailand, covering the four main components of the underlying core elements that include 19 classified elements, as shown in Table II.

(2) Query administrators and practitioners in the VSPO of Thailand. These are the tools used to collect information for the development of component-oriented confirmation. It is a survey of leaders' and practitioners' opinions in the VSPO of Thailand about training program factors to develop the competency of ROO in the VSPO in Thailand in the condition that spam to the elements which can be used to study the training program factors to develop the competency of ROO in the VSPO in Thailand is the precision of the structure as the structure of the development of the 
(1) Module 1 (1) Trends of health system

(2) Reforming regional health

(3) Situation analysis

(4) Service plan and personal administration

(5) Fiscal and monetary, internal control and risk management

(2) Module 2 (6) Presentation of methods and data for monitoring

(7) Planning and implementation

(8) Regulation and following

(9) New management skills, system thinking, analytical thinking, synthesis thinking, conflict management style, leadership

(10) Positive thinking, conflict management process, negotiation skill, contingency management

(11) Network management, team building

(12) Project management, monitoring and data definition

(3) Module 3 (13) Presentation of methods and data for monitoring, presentation skill, conference management skill

(14) Documents

(15) Researching, learning skill, communication skill exercise, action plan workshop, preparation to study in the fields workshop

(4) Module 4 (16) Field study in the VO

(17) Field study in the communication organization

(18) Summary to adjust Strategies, KPI and action plan

(19) Summary to present for administrators in the VSPO

Table II.

Master structure of the training program factors to develop the competency of $\mathrm{ROO}$ in the VSPO in Thailand

component is qualified in analyzing the components provided in Table II. It includes 40 recruitment variables to cover the four capacities that are classified into components of ten elements, as shown in Table III.

Data collection. The data was collected using two questionnaires for collecting information from executives and practitioners in the field offices of the virtual health services:

(1) Data were collected from a sample of the executives. To obtain qualified answers, the questionnaires were sent and returned directly to get the query back from the 274 executives, representing 90.13 percent of qualified 304 target samples.

(2) To collect data from a sample of practitioners from 12 VSPO in Thailand, questionnaires were sent and returned by post to get the query back from the 664 practitioners, representing 81.07 percent of 819 target samples.

Side Core component

(1) Module 1 (1) Service plan and personal administration

(2) Fiscal and monetary, internal control and risk management

(2) Module 2 (3) New management skills, system thinking, analytical thinking, synthesis thinking, conflict management style, leadership

(4) Positive thinking, conflict management process, negotiation skill, contingency management

(3) Module 3 (5) Network management, team Building

(6) Project management, monitoring and data definition

(7) Presentation of methods and data for monitoring, presentation skill, conference management skill

(8) Researching, learning skill, communication skill exercise, action plan workshop, preparation to study in the fields workshop

(4) Module 4 (9) Summary to adjust strategies, KPI and action plan

(10) Summary to present for administrators in the VSPO

Table III.

Structure of the training program factors to develop the competency of ROO in the VSPO in Thailand 
JHR

32,1

52

Data analysis. Research data analysis was divided into two episodes according to the purpose of this research. They are as follows:

(1) EFA, the composition extracted by principal component analysis method rotation axis and angle pattern elements with varimax rotation by using IBM SPSS statistics version 23 analysis.

(2) CFA from the data of administrators and practitioners with the second confirmatory factor analysis using AMOS Program.

(3) PA from the data of the second-order CFA by using AMOS Program.

\section{Results}

Analyzing with EFA to analyze 40 variables

The results for testing the suitability of the variables used in this study were obtained by conducting Kaiser-Meyer-Olk in test to measure the sampling adequacy (MSA). KMO or MSA at 0.959 , which is over 0.80 , shows that the variable series is appropriate to be analyzed at a good level on the basis of the work done by[17]; and Bartlett's test of sphericity found the variables to be correlated significantly ( $p$-value $<0.001)$, which shows that different variables can be used to analyze the elements.

Results of the extraction method of principal component analysis showed communality of each variable used in the analysis of the VSPOMM for SP in the regional health service in Thailand. The total number of characters was 40 and the composition of each variable ranged from 0.670 to 0.875 - most of them tend to move in the composition of other components.

Orthogonal rotation with varimax is shown in Table IV. The results of the variable component in the restructuring and naming of the element.

Table IV showed that the variables used in the analysis can be grouped into a total of 40 elements. Each component has five elements with the eigenvalue that exceeds 1.00, which means that each component can be explained by the variance of all 40 elements with eigenvalue more than 1.00; features of all five elements could explain the variance of all 40 characters, representing 69.83 percent.

Only a single element that has a variable with maximum weight of the composition (factor loading) can be equipped into the composition of any one element. It was found that the components can be arranged into five elements; there were 40 characters and each component consisted 4 to 15 variables. Each variable element that is already in a composition has the weight of the composition in the following range: $0.50 \leqslant$ weight of the composition $\leqslant 0.81$. Due to the effects of the input variables found in some of the elements, components included variables up to 15 and the variables from different side. Researchers restructure the elements slightly so that each element consists of the same number of variables. The composition was reduced to 4 from 40 elements that were present initially. Four modified elements were given a meaningful name, consistent and cover all the variables.

Table IV.

Results of the orthogonal elements with varimax rotation

\begin{tabular}{|c|c|c|c|c|c|c|}
\hline \multirow[b]{2}{*}{ Component } & \multicolumn{3}{|c|}{ Extraction sums of squared loadings } & \multicolumn{3}{|c|}{ Rotation sums of squared loadings } \\
\hline & $\begin{array}{c}\text { Total } \\
\text { (eigenvalue) }\end{array}$ & $\begin{array}{c}\% \text { of } \\
\text { variance }\end{array}$ & $\begin{array}{c}\text { Cumulative } \\
\%\end{array}$ & $\begin{array}{c}\text { Total } \\
\text { (eigenvalue) }\end{array}$ & $\begin{array}{c}\% \text { of } \\
\text { variance }\end{array}$ & $\begin{array}{c}\text { Cumulative } \\
\%\end{array}$ \\
\hline 1 & 21.27 & 53.18 & 53.18 & 21.27 & 53.18 & 53.18 \\
\hline 2 & 2.44 & 6.09 & 59.27 & 2.44 & 6.09 & 59.27 \\
\hline 3 & 1.69 & 4.22 & 63.49 & 1.69 & 4.22 & 63.49 \\
\hline 4 & 1.51 & 3.76 & 67.25 & 1.51 & 3.76 & 67.25 \\
\hline 5 & 1.03 & 2.58 & 69.83 & 1.03 & 2.58 & 69.83 \\
\hline
\end{tabular}


Results of the second-order CFA

The results of the second-order CFA were analyzed to confirm that the four elements listed above are the four aspects. The results indicated that the four aspects are main elements. To obtain a model of the real overall training program in the form of training program with the help of main elements is desirable, as detailed in Figure 1 and Table V. The results of the second-order CFA in the form of administrative offices are desirable as shown in Table V and Figure 1.

Table $\mathrm{V}$ and Figure 1 found that the model element of training program factors to develop the competency of ROO in the VSPO in Thailand is desirable and consistent with the empirical data of the administrators and practitioners due to a statistical measure of harmony through them. It shows that the model has a good construct validity. It can be seen that the training program factors to develop the competency of ROO in the VSPO in

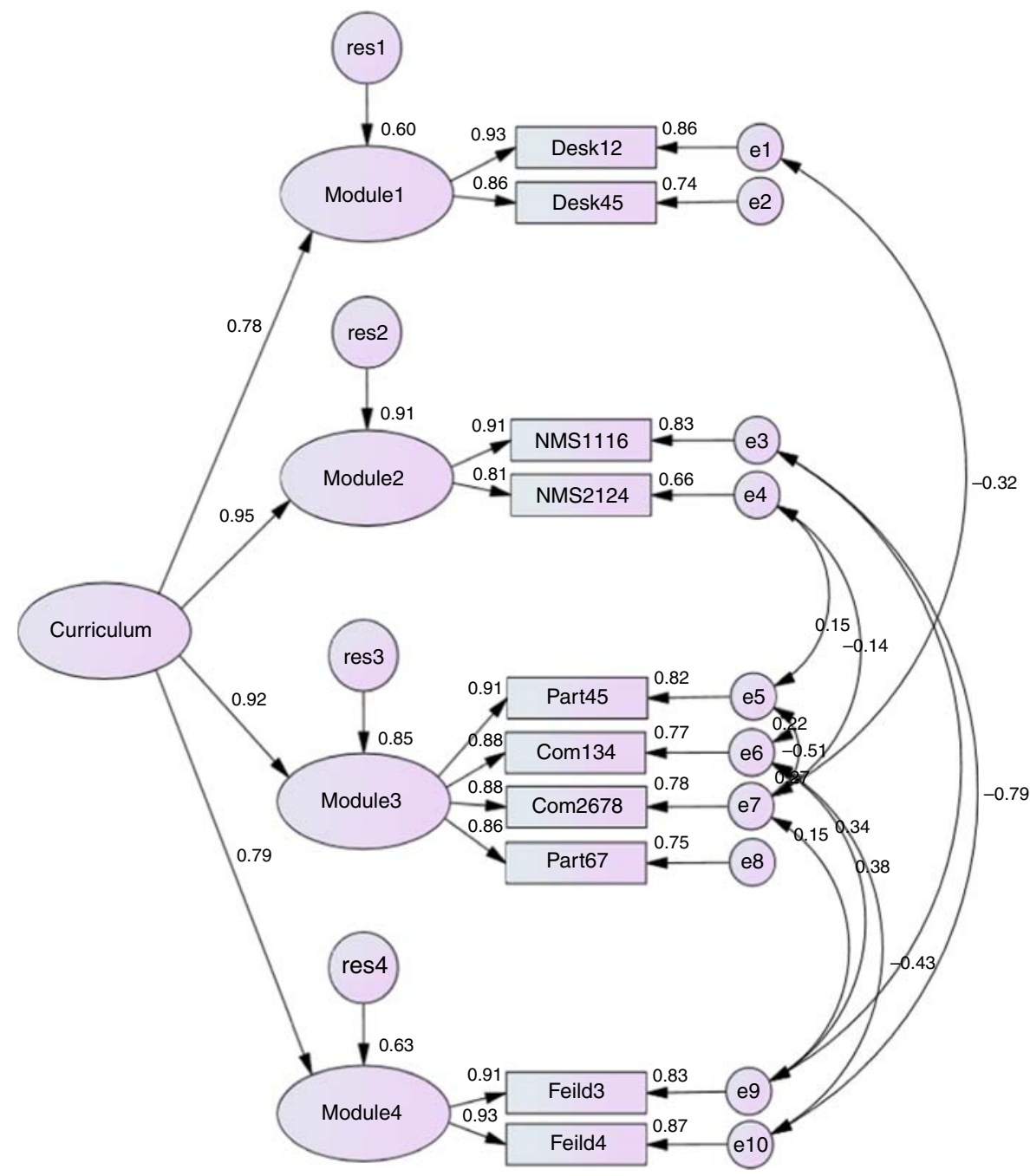

Factors to develop the competency of $\mathrm{ROO}$ in VSPO
Figure 1.

The second-order CFA model of the training program factors to develop the competency of ROO in the VSPO in Thailand 
JHR

32,1

54

Thailand is desirable since it includes the following four aspects: Module 1: health sector reform and regional health system consists of two elements; Module 2: management, leadership and partnership for regional health consists of two elements; Module 3: competency of ROO consists of four elements; and Module 4: field study consists of two elements.

There were a total of ten components: DESK12 (SP and personal administration); DESK45 (fiscal and monetary, internal control and risk management); NMS1116 (new management skills, system thinking, analytical thinking, synthesis thinking, conflict management style, leadership); NMS2124 (positive thinking, conflict management process, negotiation skill, contingency management); PART45 (network management, team building); PART67 (project management, monitoring and data definition); COM134 (presentation of methods and data for monitoring, presentation skill, conference management skill); COM2678 (researching, learning skill, communication skill exercise, action plan workshop, preparation to study in the fields workshop); FEILD3 (summary to adjust strategies, key performance indicator (KPI) and action plan); and FEILD4 (summary to present for administrators in the VSPO).

\section{Results of $P A$}

Following on from the CFA, the investigator has analyzed the PA of the VSPO administration to show the reason of influence between the variables in all ten observed variables and four latent variables. PA is the root-cause analysis performed by the researchers who want to find the dependent variables (management) that were influenced by the independent variables (setting, material, man) in order to analyze and audit that whether the causal relationship model and the effect of the real phenomenon are in conformity or conflict with the theoretical relationship. To explain the causes of the phenomenon, researchers have to study to gain knowledge and formulate a theory to analyze and set hypothesis with creating a diagram showing the influence of what they are studying. When creating a layout diagram, the reasons already mentioned can be seen. It is a way to test that the diagram above is based on the hypothesis or not by analyzing the PA. This technique was invented by[18]. To test the hypothesis, researchers used the method of calculation by using AMOS program to calculate the correlation coefficients and significance levels for each route along with the introduction of the right path. The analysis of the model showed that a causal model of VSPO administration for health services system of Thailand that researchers made was consistent with the empirical data that was collected

Table V.

Statistics measuring the harmony of the model with empirical data of the training program factors to develop the competency of ROO in the VSPO in Thailand

\begin{tabular}{lccll}
\hline Fit index & Criteria-of-fit index & Results of CFA & Consideration & Decision \\
\hline$\chi^{2}$ & $>0.05$ & 0.055 & Meet the criteria & Well \\
CMIN/df & $<2.00$ & 1.550 & Meet the criteria & Well \\
GFI & $>0.90$ & 0.991 & Meet the criteria & Well \\
AGFI & $>0.90$ & 0.975 & Meet the criteria & Well \\
ECVI & $<$ ECVI for saturated model (0.290) & 0.166 & Meet the criteria & Well \\
Model AIC & $<$ Saturated AIC (110.00) & 110.00 & Meet the criteria & Well \\
NFI & $>0.90$ & 0.995 & Meet the criteria & Well \\
CFI & $>0.90$ & 0.998 & Meet the criteria & Well \\
RMR & $<0.05$ & 0.008 & Meet the criteria & Well \\
RMSEA & $<0.05$ & 0.029 & Meet the criteria & Well
\end{tabular}

Notes: AGFI, adjusted goodness-of-fit index; AIC, Akaike information criterion; CFI, comparative fit index; CMIN/df, $\chi^{2}$ statistics and degrees of freedom ratio; ECVI, expected cross-validation index; GFI, goodness-of-fit index; NFI, normed-fit index; RMR, root-mean-square residual; RMSEA, root-meansquare-error of approximation 
(not statistically significant $p$-value $=0.450$ ), with the corresponding index of 0.98 . The results of PA are desirable as shown in Table VI and Figure 2.

Table VI and Figure 2 found that the model element of training program factors to develop the competency of ROO in the VSPO in Thailand is desirable and consistent with the empirical data of the administrators and practitioners due to a statistical measure of harmony through them. It shows that the model has a good construct validity. It can be seen that the training program factors to develop competency of ROO in the VSPO in Thailand is

\begin{tabular}{lcclc}
\hline Fit index & Criteria-of-fit index & Results of PA & Consideration & Decision \\
\hline$\chi^{2}$ & $>0.05$ & 0.450 & Meet the criteria & Well \\
CMIN/df & $<2.00$ & 1.006 & Meet the criteria & Well \\
GFI & $>0.90$ & 0.994 & Meet the criteria & Well \\
AGFI & $>0.90$ & 0.983 & Meet the criteria & Well \\
ECVI & $<$ ECVI for saturated model $(0.290)$ & 0.166 & Meet the criteria & Well \\
Model AIC & < Saturated AIC (110.00) & 110.00 & Meet the criteria & Well \\
NFI & $>0.90$ & 0.997 & Meet the criteria & Well \\
CFI & $>0.90$ & 1.00 & Meet the criteria & Well \\
RMR & $<0.05$ & 0.005 & Meet the criteria & Well \\
RMSEA & $<0.05$ & 0.003 & Meet the criteria & Well
\end{tabular}

Factors to develop the competency of $\mathrm{ROO}$ in VSPO

Table VI.

Statistics measuring the harmony of the model with empirical data of the training program factors to develop the competency of ROO in the VSPO in Thailand

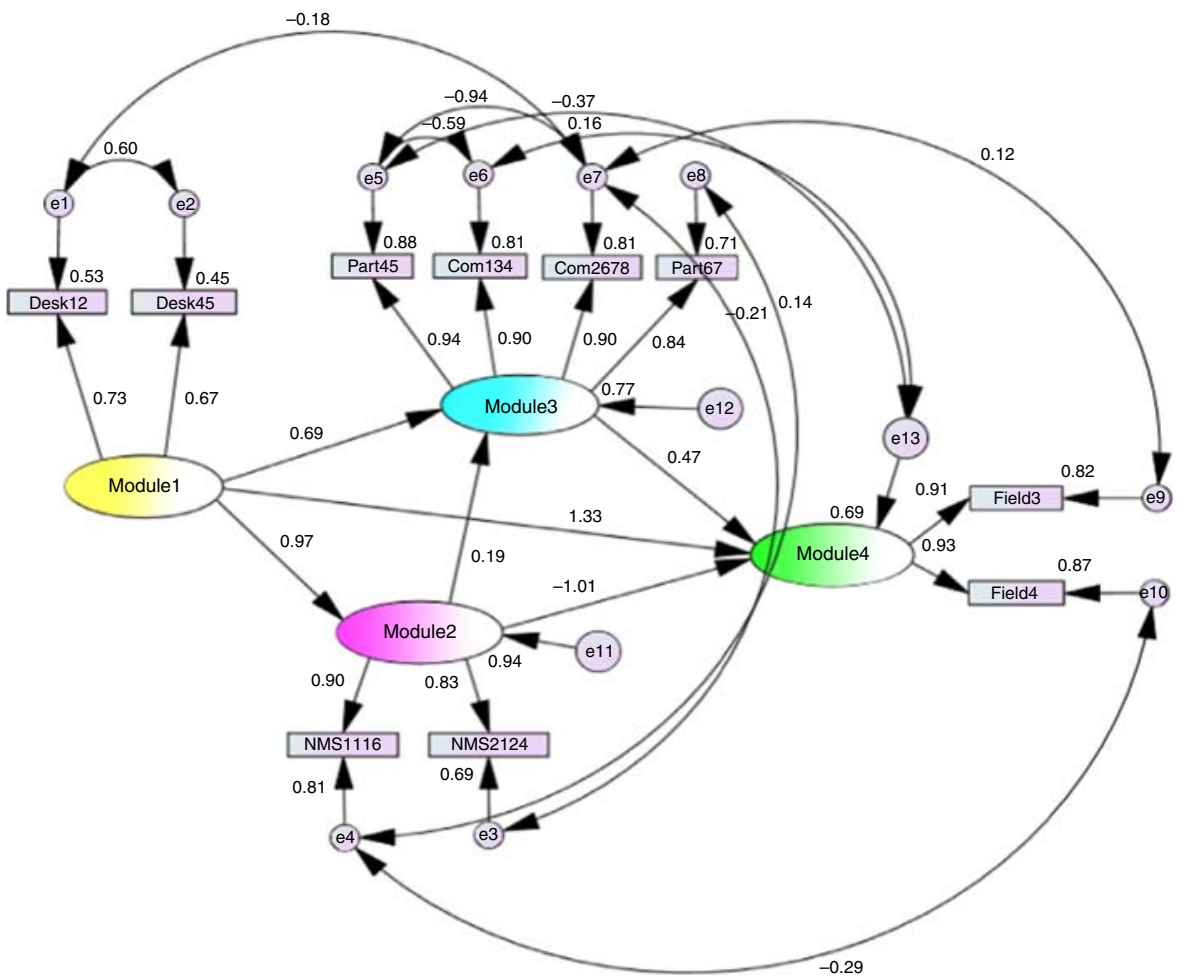

Notes: $\chi^{2}=20.124$; degrees of freedom $(\mathrm{df})=20$; probability level $(p$-value $)=0.450$; RMSEA $=0.003$
Figure 2.

The second-order CFA model of the training program factors to develop the competency of ROO in the VSPO in Thailand 
JHR

32,1

desirable; since it includes the four aspects: Module 1: health sector reform and regional health system, two elements; Module 2: management, leadership and partnership for regional health, two elements; Module 3: competency of ROO, four elements; and Module 4: field study, two elements.

\section{Conclusions}

(1) The results of the survey training program factors to develop the competency of ROO in the VSPO in Thailand from the data of the administrators and practitioners in the VSPO have found that the core factors of training program of four aspects (three core factors : knowledge, skills, and practices for SP administration) are as follows: Module 1: health sector reform and regional health system consists of two elements; Module 2: management, leadership and partnership for regional health includes two elements; Module 3: competency of ROO consists of four elements; and Module 4: field study consists of two elements. Element 10 is a component of the 40 selected variables.

(2) Results of the second-order CFA from the data of the administrators and practitioners in the VSPO in the regional health service in Thailand indicated that the elements of the training program including four aspects are main elements and ten sub-elements have a good construct validity. Because the model is consistent with the empirical data, it is in good shape. The statistics measure the harmony through all as follows: the resulting management desirable model fits with a chisquare of 30.997, 20 degrees of freedom (DF); and it is not statistically significant with a $p$-value of $0.055 . \chi^{2}$ statistics and degree of freedom ratio (CMIN/df) is 1.550 (although there is no consensus regarding an acceptable ratio for this statistic, recommendations range from as high as 5.0[19] to as low as 2.0[20]. The various goodness-of-fit indices are also acceptable. The goodness-of-fit index (GFI) is 0.991; and the adjusted goodness-of-fit index (AGFI) is 0.975 (traditionally an omnibus cutoff point of 0.90 has been recommended for the GFI; however, simulation studies have shown that when factor loadings and sample sizes are low, a higher cut-off of 0.95 is more appropriate[21]. The expected cross-validation index (ECVI) for saturated model is 0.166 (the model's ECVI is compared with the ECVI of independent model and the ECVI of saturated model, if the model has good overall fit, its ECVI value should be lower than both the ECVI values of the other two models[22], saturated Akaike information criterion (AIC) is 110.00 (probably the best known of these indices is the AIC or the consistent version of AIC (CAIC), which adjusts for sample size)[23]. These statistics are generally used when comparing non-nested or non-hierarchical models estimated with the same data; and it indicates to the researcher which of the models is the most parsimonious. Smaller values suggest a good fitting, parsimonious model; however, because these indices are not normed to a $0-1$ scale, it is difficult to suggest that a cut-off other than that the model that produces the lowest value is the most superior. It is also worth noting that these statistics need a sample size of 200 to make their use reliable[24]. The normed-fit index (NFI) is 0.995 (more recent suggestions state that the cut-off criteria should be $\mathrm{NFI} \geqslant 0.95[25]$. The comparative fit index (CFI) is 0.998 (a value of $\mathrm{CFI} \geqslant 0.95$ is presently recognized as indicative of a good fit[25]); and the root-mean-square residual (RMR) is 0.008 (values for the SMR range from zero to 1.0 with well-fitting models obtaining values less than 0.05$)[22,24]$. While the root-mean-square error of approximation (RMSEA) is 0.029 (more recently, a cut-off value close to 0.06 [25] or a stringent upper limit of 0.07[26]). On prioritizing the core elements in the descending order, we get the following list: DESK12; FEILD4; PART45; FEILD3; NMS1116; COM134; COM2678; DESK45; PART67; and NMS2124. 
(3) Results of PA from the data of the administrators and practitioners in the VSPO in the regional health service in Thailand indicated that the elements of the training program including four aspects are main elements and ten sub-elements have a good construct validity. Because the model is consistent with the empirical data, it is in good shape. The statistics measure the harmony through all as follows: the resulting management desirable model fits with a chi-square of 30.997, $20 \mathrm{DF}$; and it is not statistically significant with a $p$-value of $0.055 . \chi^{2}$ statistics and degree of freedom ratio $(\mathrm{CMIN} / \mathrm{df})$ is $1.550[19,20]$. The various goodness-of-fit indices are also acceptable. The GFI is 0.991; and the AGFI is 0.975[21]. The ECVI for saturated model is $0.166[22]$, saturated AIC is $110.00[23,24]$, the NFI is 0.995[25]. The CFI is 0.998[25]; and the RMR is 0.008[22, 24], while the RMSEA is 0.029[25, 26].

\section{Discussions}

(1) The results of the survey of the training program factors to develop the competency of ROO in the VSPO in Thailand found that the 40 variables studied can be grouped into five elements per group. Each element has an eigenvalue more than 1.00; and all elements can explain the variance of all the variables. They were 69.83 in weight; and the composition of each variable with values ranged from 0.670 to 0.875 . It shows that the variables series is appropriate to be analyzed at a good level; and it can also be analyzed for the second-order CFA and can be used to study training program factors to develop the competency of ROO in the VSPO in Thailand, since these parameters varied with the documents and research support by the study of related documents and research widely. Therefore, the parameters and structure of the training program factors of four large aspects include health sector reform and regional health system, management, leadership and partnership for regional health, competency of ROO, and field study. The 40 variables are grouped into five elements, which the researchers chose to use as variables with the weight ranging from 0.504 to 0.814 and restructure elements slightly to have four main aspects that cover all the 40 variables present originally. Then, researchers checked the validity again by a second confirmatory factor analysis.

(2) Results of the second-order CFA of training program factors to develop the competency of ROO in the VSPO in Thailand found that variables model of the second-order CFA of training program incorporates elements of the main four aspects; and the ten elements are appropriate at a good level, and it is consistent with the empirical data of the administrators and practitioners in the field offices of the Health Service Virtual. The statistics measure the harmony of all in the form of training program factors. The second-order CFA that was developed has a construct validity which can be used to study the training program factors of desirable characteristics, indicating that the model has a good precision, since the variables and elements, such as related documents and research support, are analyzed through EFA and CFA.

(3) Results of PA found that variables model of the second-order CFA of training program incorporates elements of the main four aspects; and the ten elements are appropriate at a good level. This is consistent with the empirical data of the administrators and practitioners in the field offices of the Health Service Virtual. The statistics measure the harmony of all in the form of training program factors. The second-order CFA that was developed has a construct validity which can be used to study the training program factors of desirable characteristics, indicating that the model has a good precision, since the variables and elements, such as related documents and research support, are analyzed through EFA and CFA. 


\section{Suggestions}

(1) Suggestions for bringing research results to the user. Elements of training program factors to develop the competency of ROO in the VSPO in Thailand were developed related to documentation and research support and have been checked for accuracy by analyzing them the second time with EFA and the second-order CFA, and were found to have a good construct validity. It can be used to study the training program factors to develop a training program to develop the competency of ROO in the VSPO in Thailand in the future of research and development.

(2) Suggestions for further research. Elements of training program factors to develop the competency of ROO in the VSPO in Thailand were developed to suit the job responsibilities, knowledge, skills, and practices for $\mathrm{SP}$ administration of personnel as practitioners in the VSPO. They may use these elements in considering the responsibilities, knowledge, skills, and practices, and extensive or complex of the personnel. Such elements can be used in training courses, research, on-the-job training, etc. Moreover, these should also be consistent with the responsibilities, knowledge, skills, and practice of the personnel. As analyzed and determined by the validity of the new structure by EFA and/or CFA, the higher the academic standing, the higher the responsibility they may get. Elements of training program factors to develop the competency of ROO in the VSPO in Thailand were analyzed to study other training programs that need to improve variable and elements to suit the content of training program. In particular, factors and elements of knowledge, skills, and practices in virtual organization will vary according to the administrative structure of the office, training program structure, and the responsibility of the personnel; then, the composition is adjusted and varied to determine the validity of new structure by EFA and/or CFA, PA likewise.

\section{References}

1. Gupta JND. Association for Information Systems Proceedings of the Americas Conference on Information Systems, 1997 Aug 15-17; Indianapolis, IN, pp. 417-19, 1997.

2. Afsarmanes H, Camarinha, M. Processes and foundations for virtual organizations. Kluwer Academic Publishers; 2004.

3. Malone $\mathrm{M}$, Davidow W. The virtual corporation: structuring and revitalizing the corporation for the 21st century. New York, NY: HarperCollins; 1992.

4. Introna LD, More H, Cushman M. The virtual organization - technical or social innovation? Lessons from the film industry. 2017; Working Paper No. 72 [cited 2017 May 26]. Available from: http://is.lse.ac.uk/wp/pdf/wp72.pdf

5. Boonda P, Markmee P, Preedeekul A, Nissayan J, Saksripanich S. Developing an appropriate virtual service provider office management model for service plan in the second regional health service of Ministry of Public Health in Thailand. Proceedings of Second International Conference on Global Public Health, Jul 3-4, 2014; Negombo, pp. 54-9.

6. Olson MH. Remote office work: changing work patterns in space and time. Commun ACM. 1983; 26(3): 182-7. doi: $10.1145 / 358061.358068$

7. Venkatesh A, Vitalari NP. An emerging distributed work arrangement: an investigation of computer-based supplemental work at home. Manage Sci. 1992; 38(12): 1687-706. doi: 10.1287/ mnsc.38.12.1687

8. Giuliano VE. The mechanization of office work. Sci Am. 1982; 247(3): 148-64.

9. Hiltz SR. The 'virtual classroom': using computer-mediated communication for university teaching. J Commun. 1986; 36(2): 95-104. doi: 10.1111/j.1460-2466.1986.tb01427.x 
10. Malone M, Davidow W. Virtual corporation. Forbes. 1992; 150(13): 102-7.

11. Travica B. The design of the virtual organization: a research model. Proceedings of the American Conference on Information Systems, AIS, Indianapolis, IN, 1997 Aug 15-17, p. 417-9.

12. Faucheux C. How virtual organizing is transforming management science. Commun ACM. 1997; 40(9): 50-5. doi: 10.1145/260750.260766

13. Cochran WG. Sampling techniques. 2nd ed. New York, NY: John Wiley and Sons; 1963.

14. Godden B. Sample size formulas. 2017 [cited 2017 May 26]. Available from: http://williamgodden. com/samplesizeformula.pdf

15. Cochran WG. Sampling techniques. 3nd ed. New York, NY: John Wiley \& Sons; 1977.

16. Siddiqui K. Heuristics for sample size determination in multivariate statistical techniques. World Applied Sciences Journal. 2013; 27(2): 285-7. doi: 10.5829/idosi.wasj.2013.27.02.889

17. Kim JO, Mueller CW. Introduction to factor analysis: what it is and how to do it. Beverly Hills, CA: Sage; 1978.

18. Wright S. The method of path coefficients. Annals of Mathematical Statistics. 1934; 5(3): 161-215.

19. Wheaton B, Muthén B, Alwin DF, Summers GF. Assessing reliability and stability in panel models. Sociol Methodol. 1977; 8: 84-136. doi: 10.2307/270754

20. Tabachnick BG, Fidell LS. Using multivariate statistics. 5th ed. New York, NY: Allyn and Bacon; 2007.

21. Shevlin M, Miles JNV. Effects of sample size, model specification and factor loadings on the GFI in confirmatory factor analysis. Pers Individ Dif. 1998; 25(1): 85-90. doi: 10.1016/S01918869(98)00055-5

22. Byrne BM. Structural equation modeling with LISREL, PRELIS and SIMPLIS: basic concepts, applications and programming. Mahwah, NJ: Lawrence Erlbaum Associates; 1998.

23. Akaike H. A new look at the statistical model identification. IEEE Trans on Automat Contr. 1974; 19(6): 716-23.

24. Diamantopoulos A, Siguaw JA. Introducing LISREL. London: Sage; 2000.

25. Hu, LT, Bentler, PM. Cutoff criteria for fit indexes in covariance structure analysis: Conventional criteria versus new alternatives. Struct Equ Modeling. 1999; 6(1): 1-55. doi: 10.1080/ 10705519909540118

26. Steiger $\mathrm{JH}$. Understanding the limitations of global fit assessment in structural equation modeling. Pers Individ Dif. 2007; 42(5): 893-8. doi: 10.1016/j.paid.2006.09.017

\section{Corresponding author}

Phongpisanu Boonda can be contacted at: phong2470@hotmail.com

For instructions on how to order reprints of this article, please visit our website: 